\title{
Expanding the panel of oleochemicals by altering the fatty acid hydrocarbon backbone
}

Oléagineux, Corps Gras, Lipides. Volume 10, Numéro 5-6, 365-9, Double 5-6, SEPTEMBRE-OCTOBRENOVEMBRE-DÉCEMBRE 2003, UTILISATIONS ET APPLICATIONS DES MATIÈRES PREMIÈRES RENOUVELABLES

Auteur(s) : Daniel PIOCH, Physico-chemistry of Processes and Bioenergy Laboratory, Agrifood Systems Programme, CIRAD-AMIS, 34398 Montpellier cedex 5, France <daniel.piochcirad.fr> .

Author(s) : Daniel PIOCH

Summary : While industrial oleochemistry is able to transform the carboxylic group of natural fatty acids, the fatty chain remains generally unchanged. This paper relates several attemps made at Cirad to propose alternatives through reactions performed under industrialy affordable conditions: normal or soft cracking, acylation of aromatic rings by a fatty acid, condensation of fatty acids to symetrical ketones or methyl ketones and subsequent derivatization\; theses processes share the use of cheap heterogeneous catalysts, reduced level of by-products among other "green advantages".

Keywords : fatty chain alteration, branched chain oleochemicals, ketones, catalytic cracking, branched chain waxes, branched chain amines.

\section{ARTICLE}

Auteur(s) : Daniel PIOCH

Physico-chemistry of Processes and Bioenergy Laboratory, Agrifood Systems Programme, CIRAD-

AMIS, 34398 Montpellier cedex 5, France

<daniel.pioch@cirad.fr>

Agriculture derived chemicals such as oleochemicals have proven to be very useful on the technical side and become increasingly cost competitive. As a matter of fact the elaboration of the final structures through petrochemistry requires a large number of chemical steps now performed at very large scale, whereas oleochemistry gives access readily to active structures $[1,2]$ because the starting materials result from a quite efficient and selective (bio)chemical factory, cells and enzymes. Useful chemical structures in the field of lubricants, detergents or emulsifiers for example, include an hydrocarbon chain and an heteroatomic organic, more o less polar, group. If the industrial oleochemistry provides now an easy access to various polar functions (esters of complex alcohols, nitrogen-, phosphorus- and even sulfur-containing groups derived from the sole available natural polar group - carboxylic acid or ester - the development of this industrial branch is now more limited by the number of hydrocarbon structures of natural origin available as non polar group attached to the polar head. As a matter of fact the industry needs fine tuned chemicals for surfactants or 
lubricants for example to meet various requirements (high activity, low toxicity, renewable source), whereas most of the large scale industrial oleochemical reactions concern the carboxylic group and yield derivatives having the same chain structure as the starting natural fatty acids, i.e. normal chains (figure 1).

Whereas it is well known that chain functionalization may provide useful properties, this suffers only a few exceptions such as pyrolysis of castor oil, ozonolysis of the oleic chain, guerbet alcohols or dimer acids (and iso-acid as by-product). Those give access to shorter or longer chains, or branched, or even to chains bearing a second polar group. Compared to bulk petrochemicals for example, oleochemicals would be even more attractive if we could expand this panel of available chemical structures. This is suitable either for environment protection (renewable resources, biodegradability) and for expanding marketing opportunities of oleaginous crops. This is particularly important under the present situation, i.e. limiting of green house effects, international trade agreements and constraints on oleaginous crops for food.

From the organic chemist's point of view there is a limited but not negligeable number of potential reaction sites on the most common fatty chains which in turn opens access to an impressive number of derivatives. It is almost impossible to make even a summary under the scope of the present paper. Thus, from the pure chemical side, the field is not limited.

After being the main source of organic chemicals until the start of the $20^{\mathrm{e}}$ century, the use of oleochemicals did not progress, out of the soap market, because of the competition with petrochemistry. Nowadays there is again a great interest towards oleochemicals because of environment as well as economic and social reasons. The new industrial developments are focused on functionnalized well defined oleochemicals for detergents or lubricants for example.

The present paper reports on several ways we investigated at Cirad, to produce new intermediate oleochemicals that could deal with significant market opportunities, either cracking into smaller structures or at the opposite condensation to achieve larger hydrocarbon backbones (figure 2).

\section{Cracking}

Cracking is among the reactions most widely performed at industrial scale because of its involvement at early stage for petroleum refining. In the oleochemical field this reaction is mainly applied to ricinoleic acid to get intermediate chemicals for the synthesis of polymers. We started by applying this poorly selective reaction to vegetable oils over a silica-alumina (acidic) catalyst which gave an access through a single step process - contrary to petroleum refining - to a wider range of light or medium size hydrocarbons (figure 3). This cracking was first seen as a possible route to biofuels both gasoline and diesel oil for fueling al kinds of engines - but, why not to see it now also as an access to those commodities (hydrocarbons) today available from non renewable origin [4-7]. Except in some special places in the world (very isolated areas like islands), cracking is of course not cost efficient today but it depends on the availability and on price evolution of crude petroleum. Later the catalytic cracking of capric acid and methyl oleate as model compounds was investigated over various heterogeneous catalysts (kaolinite, montmorillonite, silica-alumina, hydrotalcite and alumina) [8] because it allows a better selectivity compared to thermal cracking [9] (figure 3). The chemical composition of condensed and gaseous products had been determined to assess the selectivities. The bifunctionality of the oleate leads to a wide panel of hydrocarbons with these 
catalysts but the saturated acid shows an interesting selectivity for olefins over alumina or hydrotalcite $[8,10]$. With octanoic acid $[11,12]$, the selectivity for olefins as a whole is higher than $60 \%$, about $25 \%$ for the sole C15 fraction under appropriate conditions of temperature and residence time, whereas under high reactor temperature $\left(500^{\circ} \mathrm{C}\right)$ shorter olefins are favored. Mechanistic investigations showed that the most probable pathway with alumina involves condensation of two fatty acid molecules to the C15 symetrical ketone (di-heptyl ketone) then subjected to reduction-dehydration to yield olefins and/or to cracking itself (figure 4). These classes of compounds from renewable origin and rather clean cracking process could once replace similar fractions obtained currently from petroleum.

Out of the cracking which is not a very selective route although we could orientate to useful products, at the opposite we also investigated condensation reactions as an access to larger structures.

\section{Acylation by a fatty acid}

Alkylaromatics are among the most common petroleum based intermediates used for producing surfactants (linear alkyl benzene sulfonates). With the objective of providing an hyphen between petro- and oleochemistry the acylation of aromatic hydrocarbons, a Friedel-Crafts reaction (figure 5), was tried, successfully, over acidic solid mineral catalysts instead of using a "classical" homogeneous Lewis acid catalyst such as $\mathrm{AlCl}_{3}$. For example a $\mathrm{Ce}^{3+}$ exchanged faujasite type zeolite leads to aryl alkyl ketones with a selectivity of $99 \%$; yields showed a bell shaped curve, prefered starting fatty acids being from C8 to $\mathrm{C} 18$ owing to increasing electron donating effect of the fatty chain; then for longer fatty acids the steric effect overpass the electronic influence. When the reagent is an alkylated aromatic ring like toluene for example, the selectivity for the para isomer is $95 \%$ or better, owing to the shape selectivity brough by the narrow channels of the faujasite structure of this acidic catalyst [13]. In comparison another solid acid catalyst like an $\mathrm{Al}^{3+}$ or $\mathrm{Ce}^{3+}$ exchanged montmorillonite - a layered aluminosilicate without narrow channels - shows a selectivity for the para isomer close to that obtained with the reference homogeneous catalyst $\mathrm{AlCl} 3$ [14]. Those pure alkyl aromatic ketones half based on a renewable resource are thus obtained easily with a high yield and with a cheap catalyst, and owing to their structure close to alkyl aromatics already used [15], they may then undergo a second step to reach active series as surfactants or lubricants for example.

\section{Ketonic condensation}

We already talked about condensation of fatty acid to ketone, as an intermediate product, in the course of soft catalytic cracking over alumina. It has been another research target to try to stop at the ketone stage. The condensation of two fatty acids into ketones over an uncommon heterogeneous catalyst (figure 6), a bauxite, has been quite deeply investigated, in particular the properties of this "green", uncommon catalytic system, as a route to a wide panel of oleochemicals, just like fatty acids, methyl esters and fatty alcohols [16]. When starting from lauric, palmitic or oleic acids for example, two classes of compounds can be obtained, a symmetrical (long chain) ketone and a methyl ketone as a by-product (along with the corresponding alcanes or olefins), from the degradation of the former under the thermal conditions used $\left(350-390^{\circ} \mathrm{C}\right)$ [17]. Contrary to the alumina alone already investigated the bauxite is a complexe mixture of oxides and the catalytic activity for ketonic condensation is a function of the iron content, as confirmed by Mössbauer 
spectroscopy, the optimum between conversion and selectivity being in the range of $20 \%$ (wt as $\mathrm{Fe}_{2} \mathrm{O}_{3}$ ). Under optimized conditions, in this case, it is possible to get the ketone at a temperature low enough to prevent the cracking itself and stay at the condensation step. The mechanism proposed on the basis of dedicated experimental work involves chemisorption of fatty acid as iron soap, decarboxylation of the soap into an adsorbed alkyl anion and then condensation of both soap and carbanion [18]. Water and $\mathrm{CO}_{2}$ are the sole stoechiometric co-products, which makes the process even greener.

Under suitable experimental conditions the selectivity for the symetrical ketone is better than $95 \%$ at conversion rate higher than $90 \%$. On the other side methyl ketones may be obtained with a selectivity better than $80 \%$ when working with a mixture of fatty acid and acetic anhydride (2/1 molar ratio) [19]. The fixed bed flow pilot reactor built at Cirad (see picture page 365) allowed producing samples of several kilograms for further functionalisation of these ketones here seen as intermediate chemicals in addition to their own functional uses (inks, polishes...) [16, 19-21].

Two promizing series of derivatives where considered by transformation of the ketone group [18], (i) the production of secondary alcohols, then esterified into fatty acid esters (waxes) and (ii) nitrogen containing compounds like amines and quaternary ammonium salts (figure 7). Need to mention that those derivatives of ketones can be considered as having a branched structure and actually this was the objective of the work, on the basis of known effect of a side chain on physical and physicochemical properties. Catalytic chemical processes compatible with industrial application where worked out. In particular for getting the amino derivatives, the Leuckart reaction was chosen and "heterogeneized" with a selected (solid) catalyst, bringing a new feature for this well known reaction among classical homogeneous phase organic chemistry and then it was optimized to achieve a selectivity of 92-99\% while having an almost complete conversion of the starting ketone [22].

Dozens of derivatives from ketones, covering the range of carbon condensation of C7 to C35 where synthetized and their properties checked (melting point, viscosity, wetting, foaming, biocide, biodegradability...) ; some where then tested for application by private partners either in France or in Malaysia. In all cases, as expected, the branched structure of the fatty chain brought different features compared to normal (linear) ones. Among others, the area per polar head of mono alkyl trimethyl ammonium salts, is much greater than that of the corresponding di-alkyl salt having the same carbon condensation; thus surface coverage is more efficient while using a lower amount of active product. A consequence of branching on the carbon adjacent the nitrogen atom to (not bearing the second chain also attached to the heteroatom itself), access to the polar group should be easier for interacting with an adsorption site on a solid surface for example [23]. In the case of wax esters, rheological and low temperature properties which are key points for lubrication for example, where adapted by changing the carboxylic acid used for esterifying the intermediate secondary alcohol ; esters from short/ medium/long chain, saturated or monounsaturated fatty acids and dibasic acids, were obtained even from those hindered secondary alcohols $[24,25]$. These alcohols themselves when seen as end products show interesting properties for cosmetics [26].

\section{Conclusion}

This short report shows examples based on a an analysis of the existing industrial oleochemical production and on a chemical strategy, opening an "easy" access to intermediate chemicals, either hydrocarbons or heteroatomic molecules; this as an attempt to fill up the gap between the rather 
poor panel of natural feedstocks (fatty acids) currently available on one side and the wider range of petrochemicals marketed today or useful active compounds expected by the formulators downstream on the other side. To achieve this goal we relied on using chemical catalysis [27], "heterogeneization" of the catalytic system for working under a continuous process or for an easy separation of the catalyst when working under batch conditions, choosing a cheap and readily available catalyst. This and the investigation of the chemical mechanism where of course key points for improving the selectivity, boosting the productivity of the reactor, and thus lowering the price of these products with the aim to fit a market large enough to justify starting a production. From the technical point of view targetting branched structures was definitely a good choice. Finding markets for the "ketone path" needs private companies ready to invest in this chemistry (heterogeneous catalysis and/or high temperature), uncommon in the field of oleochemistry but daily used in petrochemistry. This is another point to be considered for giving more chances to innovation to come out. It is a fact that restructuring the fatty chain involves working on the very stable $\mathrm{C}-\mathrm{C}$ bonding, thus needing high temperature reactions to overcome the high activation energy of most of the reactions in this field. On the basis of the above expertise, we are now investigating chain functionalisation at the $\mathrm{C}=\mathrm{C}$ double bond, through catalytic processes able to be performed by existing reactors in today oleochemical plants. Integrated Green Chemistry (renewable resources, environment friendly processes, low toxicity and biodegradable products) offers to oleochemists a wide area to be explored.

\section{Acknowledgments:}

The author thanks colleagues and co-workers from Cirad - N. Chirat, N. Fargier, M. Garces, J. Graille, P. Guiffrey, C. Henry, R. Lescure, P. Lozano, C. Pannuzzo, C. Rasoanantoandro, N. Torres, V. Vidal ; from Ecole Nationale Supérieure de Chimie de Montpellier, A. Finiels, P. Geneste, A. Guida, C. Moreau ; Institut National Polytechnique de Lorraine, F. Billaud, D. Archambaud, AK. Tran-Minh ; Palm Oil Research Institute of Malaysia (Porim) - Rashid Abdul Shukor, Tang Thin Sue ; Université de Montpellier-2, JC. Jumas, J. Rouvière ; Valagro, Hoang Le Chiên.

The work was funded by Cirad, french Ministry of Industry (92L0402), french Ministry of Foreign Affairs, Ademe-Agrice (95 01066 ; 9901070 ) and Porim.

\section{REFERENCES}

1. PEL A. Fatty Acids : a Versatile and Sustainable source of Raw Materials for the Surfactant Industry, OCL $2001 ; 8-2: 145-51$.

2. CLAUDE S. Oleochemistry as an Opportunity to Consolidate the Sustainable Development of European Oil Crops, an Updated Prospect, OCL 1999 ; 6-5 : 418-27.

3. PIOCH D. Composés nouveaux en lubrification : perspectives d'innovation. Journée techniques Biomasse, Biolubrifiants de l'ADEME (French Agency for Energy Management), May 10 2001, Paris, France. 
4. RASOANANTOANDRO MC. Transformation des huiles végétales par voies thermique et catalytique. PhD thesis, Université des Sciences et Techniques du Languedoc, Montpellier, 1986.

5. PIOCH D, GRAILLE J, GUIDA A, GENESTE P. An uncommon way to hydrocarbon fuels : products and tentative modeling of the catalytic cracking of fatty acids. JECAT'95, 26-28 avril 1995, Lyon.

6. PIOCH D, LOZANO P, RASOANANTOANDRO MC, GRAILLE J, GENESTE P, GUIDA A. Biofuels from catalytic cracking of tropical vegetable oils, Oléagineux $1993 ; 48$ : 515-26.

7. PIOCH D, RASOANANTOANDRO MC, GRAILLE J, GENESTE P. 1994, Biofuels from catalytic cracking of tropical vegetable oils. Congrès International sur I'Huile de Palme (PIPOC 93), 20-25 septembre 1993, Kuala-Lumpur, (Malaisie, In : Proceedings of the 1993 PORIM International Palm Oil Congress, 1995 ; 297-302.

8. AK. TRANH-MINH. Conversion catalytique de dérivés de l'huile de colza, Une nouvelle voie de valorisation chimique, PhD thesis, Institut National Polytechnique de Lorraine, ENSIC Nancy, 2002.

9. ARCHAMBAUD D. Valorisation non alimentaire de l'huile de colza : pyrolyse de l'oléate de méthyle, PhD thesis, Institut National Polytechnique de Lorraine, ENSIC Nancy, 29 septembre 1997.

10. BILLAUD F, ARCHAMBAULT D, MOULUT ML, LOZANO P, PIOCH D. Upgrading of rapeseed oil : methyl oleate catalytic cracking, $2 d$ Meeting of the European Section of American Oil Chemists Society, 1-4 octobre 1998, Cagliari.

11. BILLAUD F, GUYTARD Y, TRAN MINH AK, ZAHRAA O, LOZANO P, PIOCH D. Kinetics studies of catalytic cracking of octanoic acid, Journal of Molecular Catalysis A : Chemical $2003 ; 192: 281-8$.

12. BILLAUD F, TRAN MINH AK, LOZANO P, PIOCH D. Catalytic Cracking of Octanoic Acid, Journal of Analytical and Applied Pyrolysis 2000 ; 58-9 : 605-16.

13. CHICHE B, FINIELS A, GAUTHIER C, GENESTE P, GRAILLE J, PIOCH D. Friedel-Craft acylation of toluene and p-xylene with carboxylic acids catalysed by zeolites. J Org Chem $1986 ; 51$ : 2128-30.

14. CHICHE B, FINIELS A, GAUTHIER C, GENESTE P, GRAILLE J, PIOCH D. Acylation over cationexchanged montmorillonite. J Molecular Catalysis $1987 ; 42$ : 229-35.

15. HO TAN TAI L, NARDELLO-RATAJ V. The Main Surfactants Used in Detergents and Personal Care Products, OCL $2001 ; 8-2$.

16. PIOCH D, GRAILLE J. Les cétones grasses : une nouvelle classe de composés lipochimiques de base ? Oléagineux Corps Gras Lipides, vol. 1, 1994 ; 94-5.

17. PIOCH D, LESCURE R, GRAILLE J. Synthèse de cétones à longue chaîne catalysée par la bauxite, Oléagineux, Corps Gras, Lipides 1995 ; 2-5 : 386-9.

18. LESCURE R. Synthèse et propriétés de cétones aliphatiques à longues chaîne et de leurs dérivés azotés. PhD thesis, Université Montpellier II, 1995. 
19. GRAILLE J, PIOCH D. Procédé de condensation catalytique d'acides carboxyliques et/ou de leurs dérivés et son application à la préparation de cétones, alcools, amines et amides. EU patent EP 0457665A1, Application May 14 1991, CIRAD.

20. PIOCH D, LESCURE R, GRAILLE J, GENESTE P, ABDUL RASHID ABDUL SHUKOR, TANG THIN SUE. Pilot scale bauxite catalyzed synthesis of long chain ketones. Proceedings of the 1996 PORIM International Palm Oil Congress, 23-28 septembre 1996, Kuala Lumpur (Maaysia), pp. 79-89.

21. PIOCH D. Branched and other functionalized exotic oleochemicals through heterogeneous catalysis, Annual meeting of the American Oil Chemists Society, San Diego, 25-28 april 2000.

22. PIOCH D, LESCURE R, GRAILLE J. Unpublished results.

23. PIOCH D. Fatty ketones : a route new oleochemicals, International Symposium on Green Chemistry, Poitiers, May 20-23 2003.

24. PIOCH D, LOZANO P, CHIRAT N, HOANG LC, HUDRY S, GRIGNOU H, MOIGNIER L. Synthèse Lipochimique et Etude de Composés à Chaine Ramifiée pour Lubrifiants, Final report, Ademe-Agrice $9501066,1998$.

25. PIOCH D, LOZANO P, TORRES N, PANNUZZO C, GUIFFREY P, HOANG LC, BATAILLE F, MOIGNER L, GRIGNOU H, POITRAT E. Synthèse Lipochimique et Etude de Composés à Chaîne Ramifiée pour Lubrifiants Biodégradables, Final report, Ademe-Agrice 9901 070, 2002.

26. PIOCH D, VIDAL V, LESCURE R, GRAILLE J. Synthèse sur mesure d'alcools secondaires. Communication, Journées Chevreul, May 1993, Paris.

27. PIOCH D, biomasse et Catalyse : la Ressource, Journée technique de l'Ademe/Biomasse, catalyse et solvants, Paris, 16-17 mai 2000. 


\section{Illustrations}

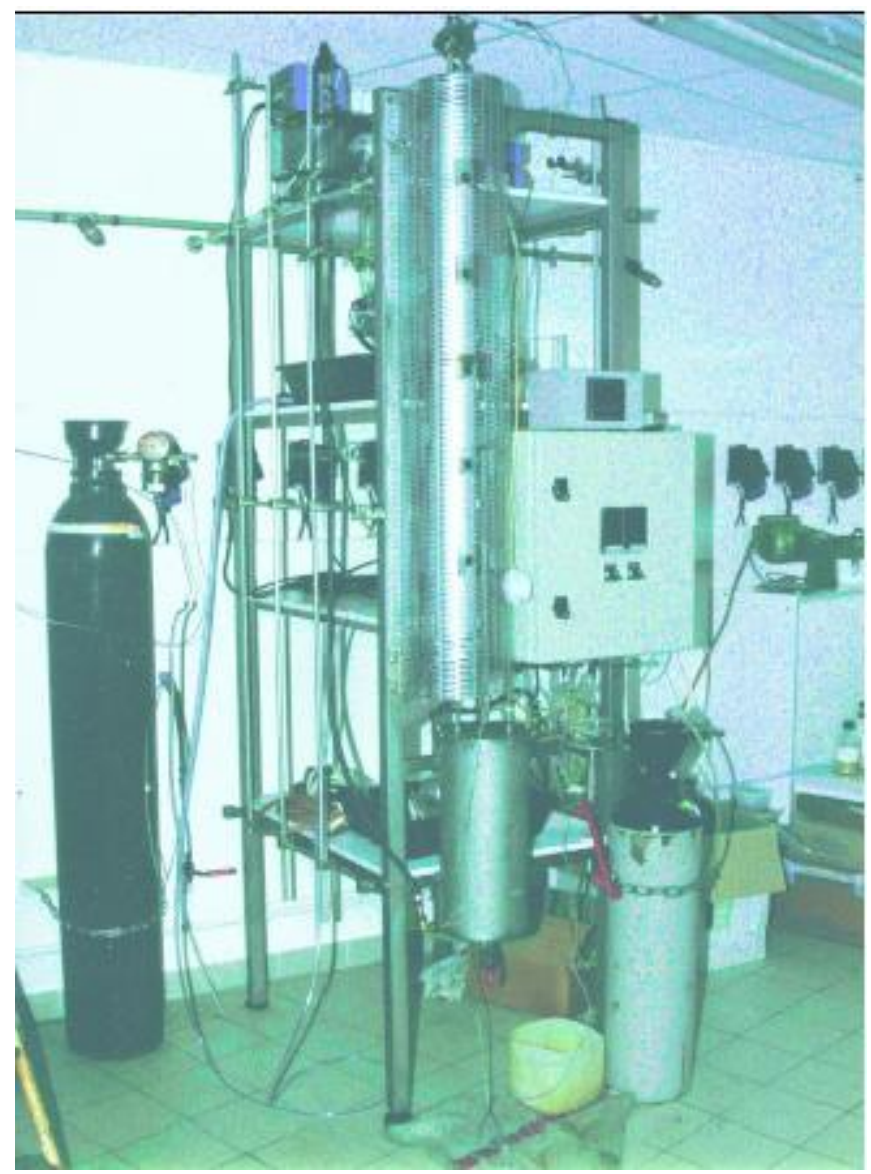

Fixed catalyst bed pilote flow reactor for fatty acid condensation to ketones.

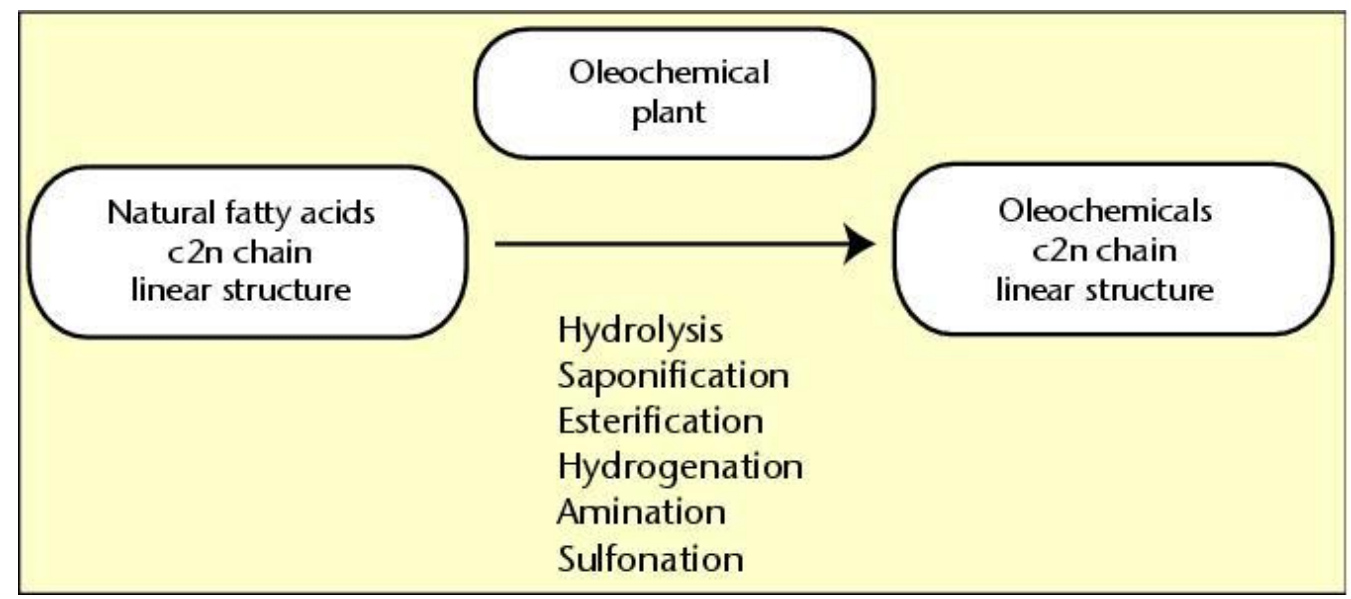

Figure 1. Industrial oleochemistry does not alter the natural acid chain 


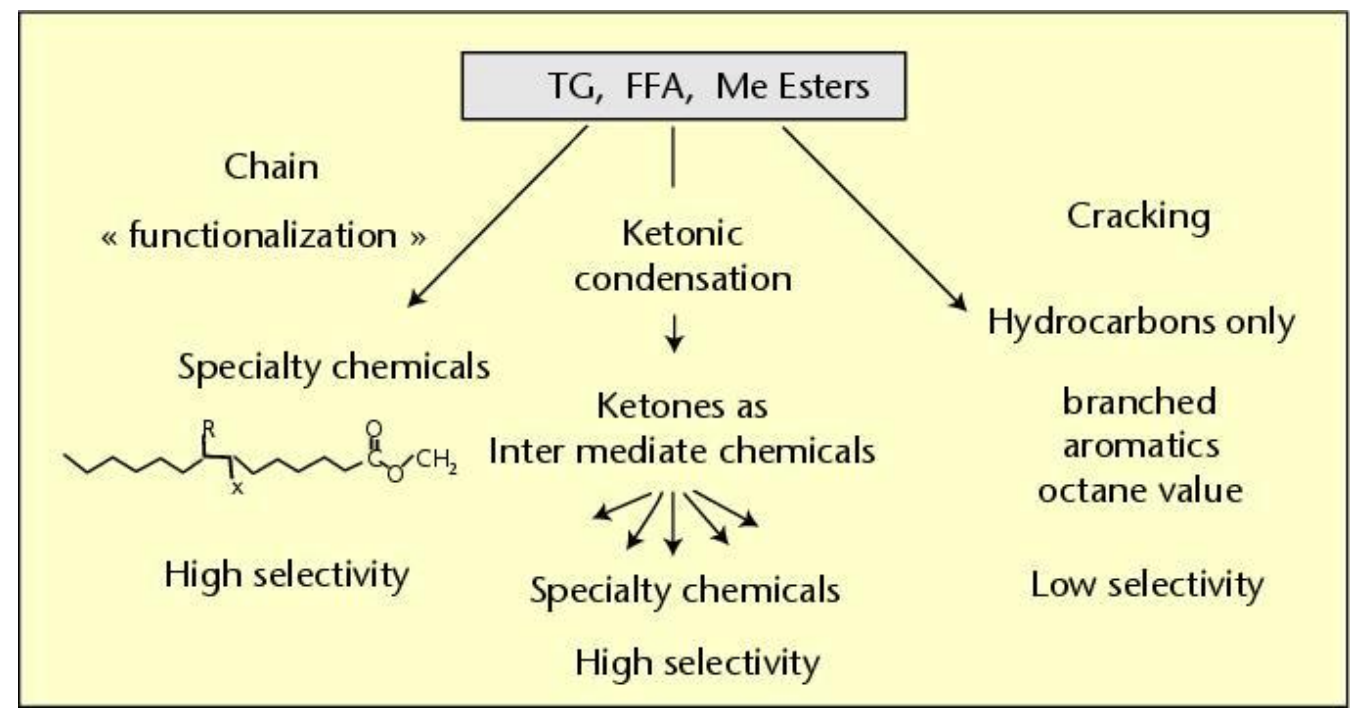

Figure 2. Examples of chemical reactions to alter fatty acid structure (from research work at Cirad).

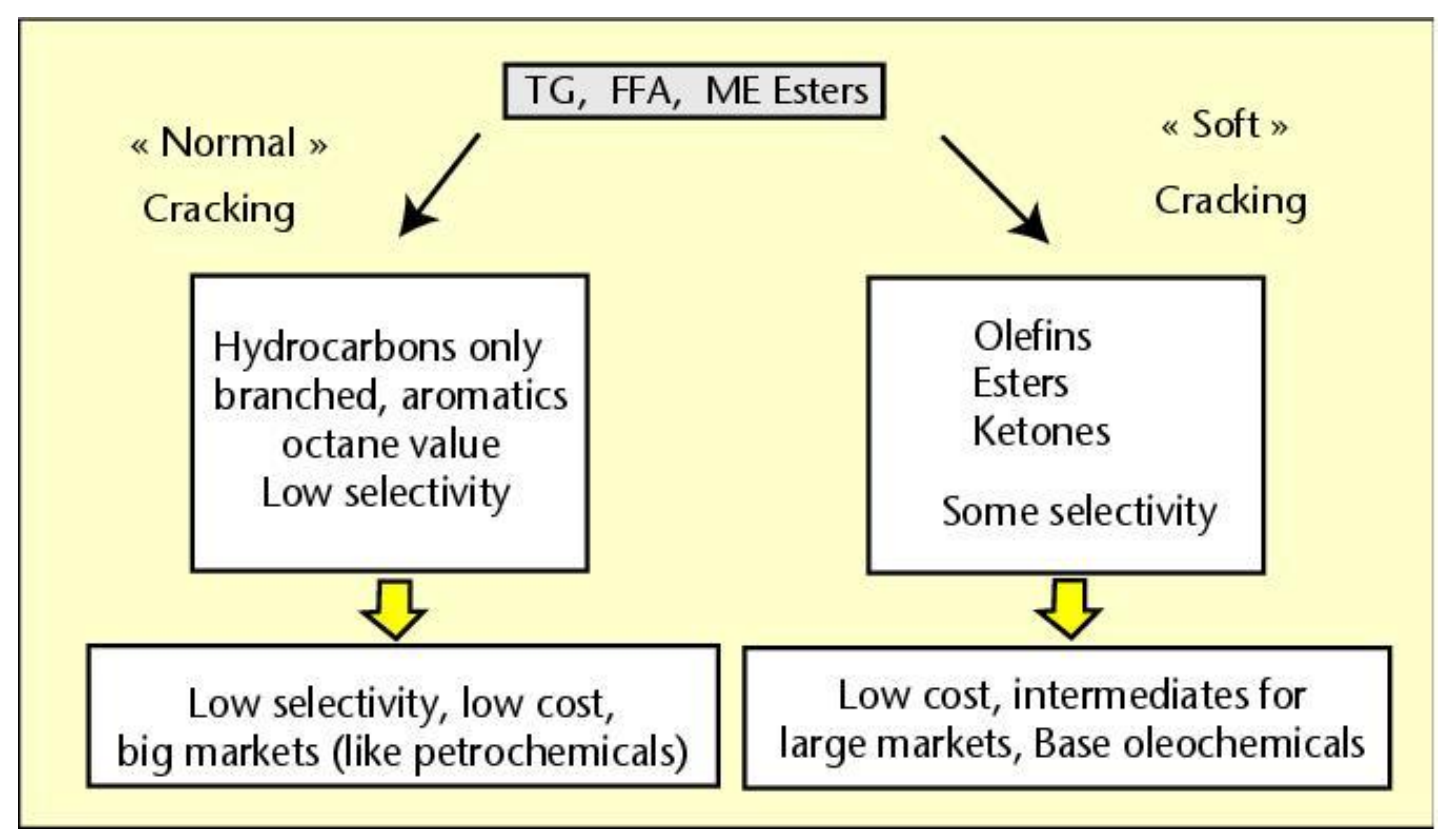

Figure 3. Oleochemicals from catalytic cracking. 


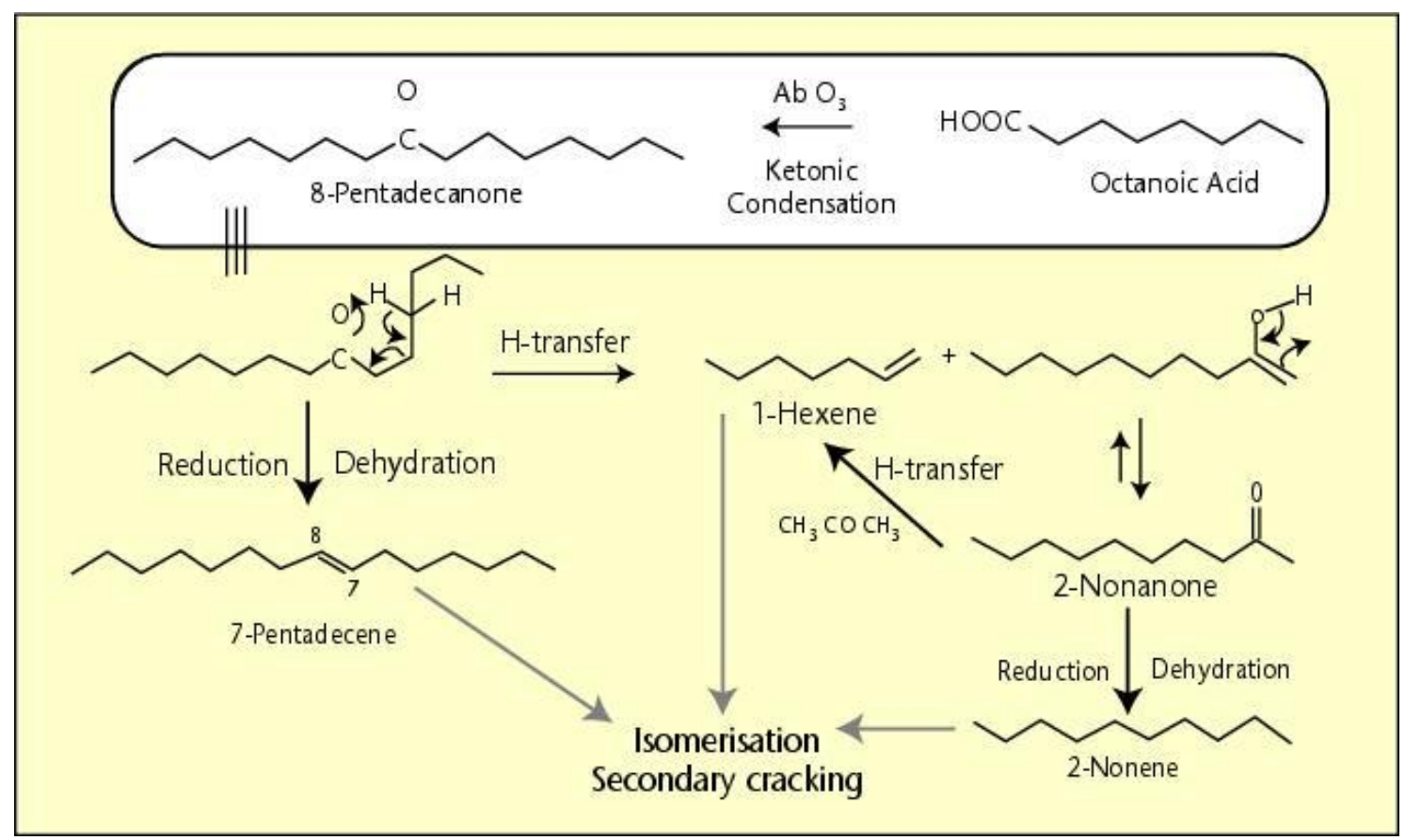

Figure 4. General reaction scheme for soft cracking of octanoic acid/alumina.

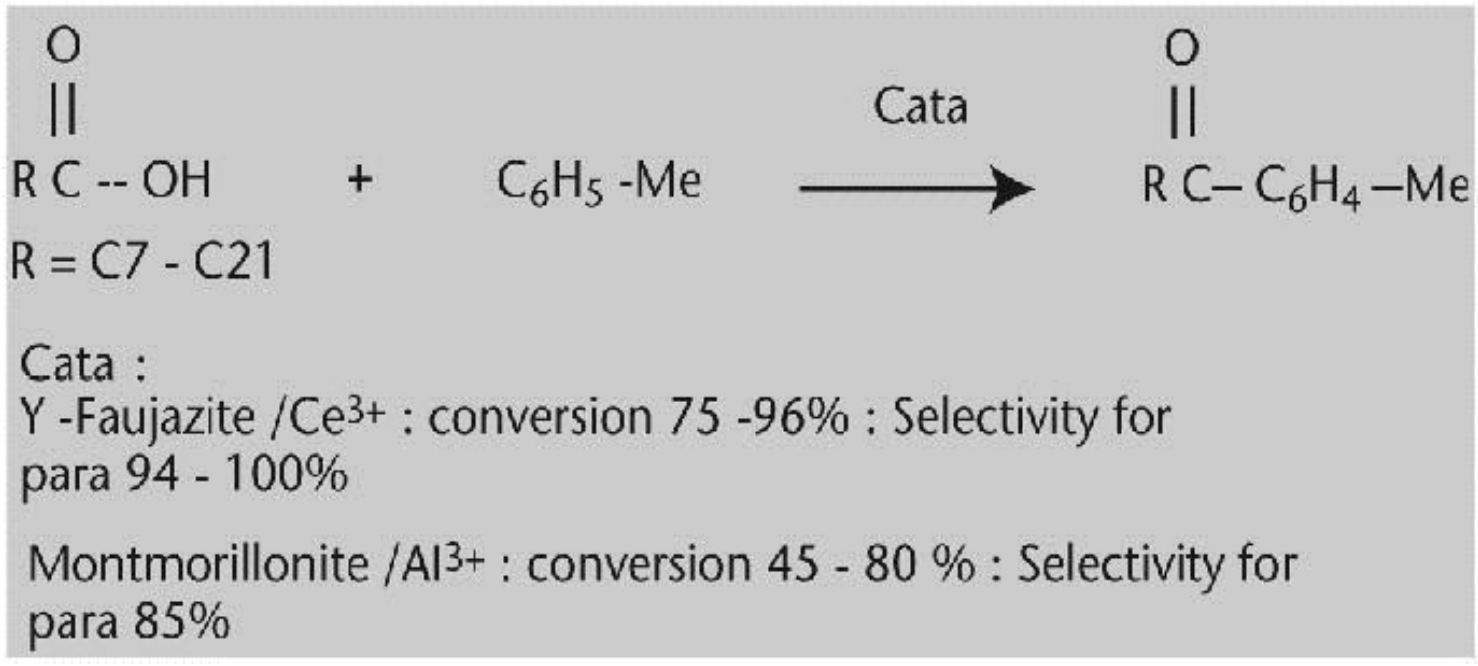

Figure 5. Ketones by Friedel-Craft acylation, an hyphenated way between petro- and oleochemistry. 


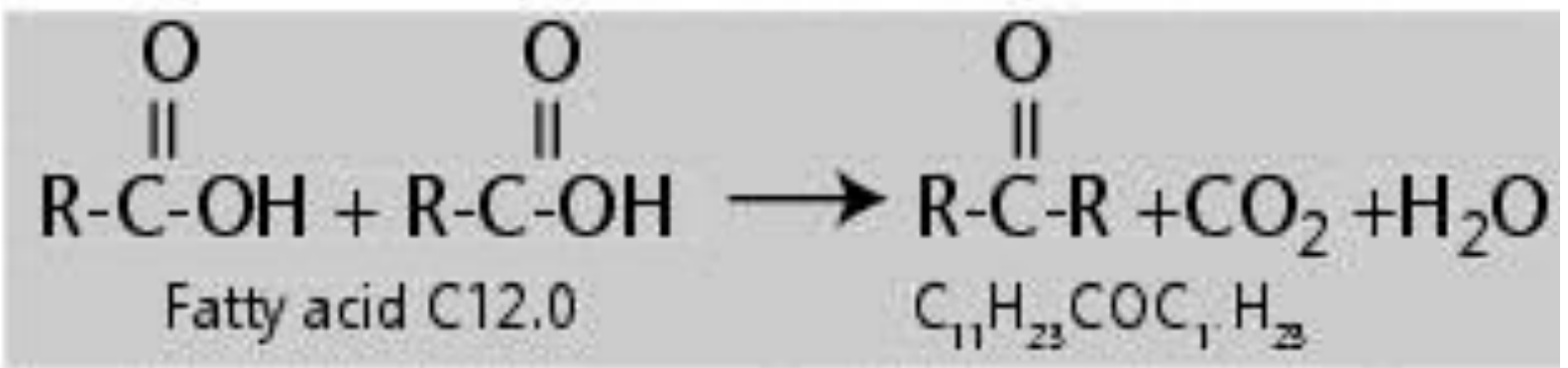

Figure 6. Decarboxylation of fatty acids to ketones.

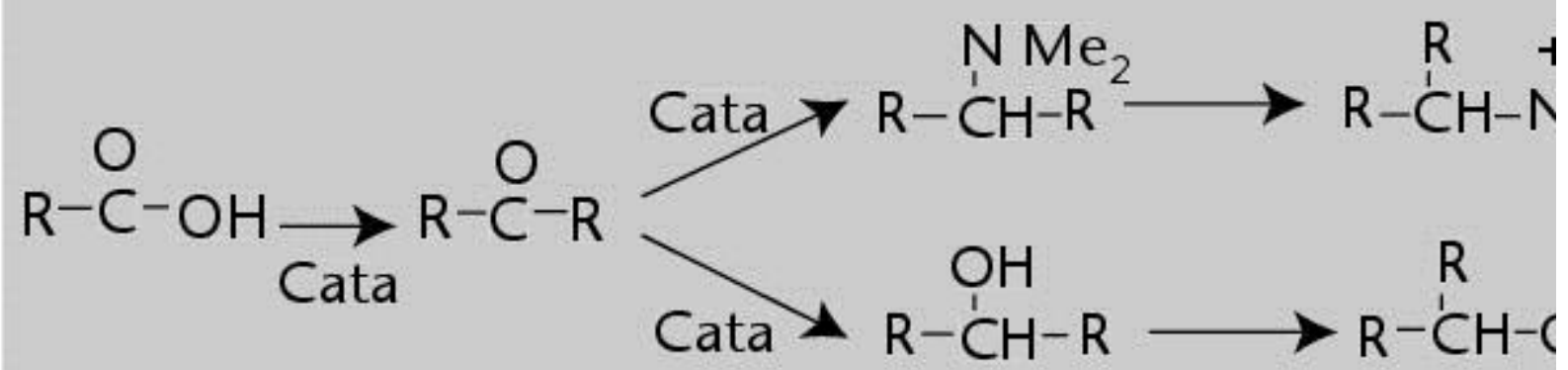

Melting temperature, viscosity, CMC, Wetting, Foaming, Biocide, Viscosity, Biodegrad

Uses as New Components in Lubricants, Detergents

Figure 7. Investigating fatty ketones as base oleochemicals, alpha branched oleochemicals (3 steps from ketones, heterogeneous catalysts). 